\title{
Updated Review of Testosterone Replacement Therapy in the Setting of Prostate Cancer
}

Michael Polchert, Igor Voznesensky, Ayman Soubra, and Wayne J.G. Hellstrom*

\begin{abstract}
Since the 1940s, elevated serum testosterone (T) levels have been infamously suggested as a causal factor in the development of prostate cancer (PCa); this time was also the dawn of both surgically and pharmacologically induced castration. However, men suffering from primary or secondary hypogonadism and who are concomitantly paradoxically at risk for developing PCa cited the adverse effects of T deficiency. In the past 25 years, researchers have published on the genetic, biochemical, and clinical outcomes of testosterone replacement therapy (TRT) in hypogonadal men. The longstanding dogma of the deleterious effects of TRT has recently been challenged, and it now appears that TRT may have an important therapeutic role in the treatment of hypogonadism in those men with either low-risk, active, or previously treated PCa. This review summarizes the latest findings on the treatment of hypogonadal men with a history of PCa, emphasizing results of clinical research studies.
\end{abstract}

Keywords: testosterone; PCa; hypogonadism; androgen treatment

\section{Introduction}

Prostate cancer $(\mathrm{PCa})$ is the most common cancer in men in the United States, with $\sim 192,000$ new cases in 2020. ${ }^{1}$ This number of annual cases is expected to rise as the population ages. For patients deemed to have low-risk PCa, active surveillance (AS) is an accepted treatment option. ${ }^{2-5}$ In cases that require treatment, surgery, radiation therapy, high-intensity focused ultrasound (HIFU), and cryotherapy are available options.

Even after successful treatment, biochemical recurrence (BCR) of PCa has been cited at a rate of 13$53 \%$ in patients after radiation therapy ${ }^{6}$ and at $30.2 \%$ 3 years post-radical prostatectomy (RP). ${ }^{7}$ It is estimated that up to $30 \%$ of males between 40 and 79 years of age are hypogonadal and $39 \%$ of males between the ages of 45-85 have a testosterone (T) level $<300 \mathrm{ng} / \mathrm{dL}$. ${ }^{8,9}$ Hence, it is not uncommon for PCa patients to also be diagnosed with $\mathrm{T}$ deficiency at any stage in their disease, whether it is before treatment, after cure, in those who have BCR, or in those who are on AS. Low T levels have been studied regarding their potential to increase the risk of PCa complications in diagnosed men, including higher incidence of extraprostatic metastasis, ${ }^{10}$ seminal vesicle invasion, ${ }^{11}$ and increased positive surgical margins. ${ }^{12}$

Irrespective of $\mathrm{PCa}$, hypogonadal men treated with testosterone replacement therapy (TRT) experience clinical benefits through increased muscle mass, bone density, mood, and sexual health/performance. ${ }^{13}$ Normalization of $\mathrm{T}$ levels is also postulated to potentially lower cardiovascular disease risk by reducing cholesterol levels, ameliorating glucose metabolism, and lessening the risk of metabolic syndrome. ${ }^{14}$ Potential side effects of TRT include polycythemia, gynecomastia, $\mathrm{BPH}$, and lowered HDL cholesterol.

The exact nature of the relationship between androgens and PCa is a particularly relevant topic given that PCa mortality has decreased by $\sim 50 \%$ in the past two decades, resulting in a significant increase in $\mathrm{PCa}$ survivors with potential for experiencing symptoms

Department of Urology, Tulane University School of Medicine, New Orleans, Louisiana, USA.

*Address correspondence to: Wayne J.G. Hellstrom, MD, FACS, Department of Urology, Tulane University School of Medicine, 1430 Tulane Avenue, 8642 , New Orleans, LA 70112, USA, Email: whellst@tulane.edu

(C) Michael Polchert et al., 2021; Published by Mary Ann Liebert, Inc. This Open Access article is distributed under the terms of the Creative Commons License (http://creativecommons.org/licenses/by/4.0), which permits unrestricted use, distribution, and reproduction in any medium, provided the original work is properly cited. 
of hypogonadism. ${ }^{15}$ In this communication, the available evidence on the safety of TRT in men at risk for or with a previous or current diagnosis of $\mathrm{PCa}$ is reviewed.

\section{Androgen Receptors and the Prostate}

In the 1940s, Huggins and Hodgkins established a connection between androgenic hormones and $\mathrm{PCa}$, laying the foundation for ADT in the treatment of PCa. They suggested that exogenous $\mathrm{T}$ would lead to increased cancer recurrence, measured by prostatic acid phosphatase (PAP) levels. This conclusion was based on the results of a very small study of three PCa patients who experienced a rise in PAP levels on administration of $\mathrm{T}$ injections, which was followed by a subsequent drop in enzyme levels after cessation of treatment. PAP has since been observed to be much less reliable than prostate-specific antigen (PSA) in the diagnosis of PCa (45\% sensitivity for PAP vs. $96 \%$ for PSA) and in monitoring disease recurrence $(25 \%$ of patients with metastatic disease presented with normal PAP levels ${ }^{16,17}$ ).

In 1996, Morgentaler et al. observed a high prevalence of PCa confirmed by biopsy in men with low total or free T levels, regardless of normal PSA levels. ${ }^{18}$ Ten years later, Morgentaler and Rhoden documented additional results wherein, in 345 hypogonadal men with a PSA of $\leq 4.0 \mathrm{ng} / \mathrm{mL}$, PCa was detected in $21 \%$ of men with $\mathrm{T}$ levels $\leq 250 \mathrm{ng} / \mathrm{mL},{ }^{19}$ compared with $12 \%$ of men with a $\mathrm{T}$ level $>250 \mathrm{ng} / \mathrm{mL}$.

Morgentaler and Traish have proposed a saturation model to describe the varying sensitivity of the androgen receptor (AR) to either physiologically low or high $\mathrm{T}$ concentrations. They postulate that maximum AR activity is achieved at low $\mathrm{T}$ concentrations and saturation is responsible for less AR activity at higher $\mathrm{T}$ concentrations. ${ }^{20}$ In human prostatic tissue, the AR is reported to become saturated and unreceptive to further increases in activity at $\mathrm{T}$ concentrations of $120 \mathrm{ng} / \mathrm{dL}$ in vitro and $240 \mathrm{ng} / \mathrm{dL}$ in vivo. ${ }^{21,22}$ Separately, Rastrelli et al. identified the $\mathrm{T}$ AR saturation at a concentration of $\sim 8 \mathrm{nmol} / \mathrm{L}(231 \mathrm{ng} / \mathrm{dL}){ }^{23}$

In one study, healthy men injected with 250 and $500 \mathrm{mg} \mathrm{T}$ per week had prostate volumes measured after 15 weeks. Despite significant elevations in free and total $\mathrm{T}$, no increase in PSA or prostate volume was observed, thereby supporting the androgen saturation theory. ${ }^{24}$ A randomized, double blind, placebocontrolled study also concluded that a 6-month TRT trial did not cause a significant increase in prostate tis- sue androgen concentrations. ${ }^{25}$ The T saturation model also has interesting implications in the development of castration-resistant prostate cancer (CRPC). It has been postulated that supraphysiologic androgen levels may even paradoxically inhibit the growth of AR expressing human PCa cells, and similar antitumor activity has been observed in breast cancer patients exposed to high concentrations of estrogen. ${ }^{26}$

\section{TRT and Risk of Developing PCa}

Researchers have evaluated whether TRT increases the risk of developing newly diagnosed PCa. We review several pertinent studies with large sample sizes and new data in this section. Although many of these reports are limited by their study design, variability of inclusion criteria, and uncertainty regarding the length of TRT, and although the RCTs have reported data with mean and median follow-up less than 5 years, it appears that TRT is safe and does not increase the incidence of PCa.

A UK-based retrospective database review published in 2019 identified 12,779 patients with "late-onset hypogonadism. ${ }^{27 "}$ The mean follow-up period was 4.6 years, though $37.3 \%$ and $9.2 \%$ of patients received follow-up for at least 5 and 10 years, respectively. The use of TRT in that population did not result in increased risk of $\mathrm{PCa}$ (hazard ratio $[\mathrm{HR}]=0.97[95 \%$ confidence interval; CI 0.71-1.32) in an overall analysis, nor when propensity score matching was applied $(\mathrm{HR}=0.87,95 \%$ CI $0.56-1.36) .^{27}$

In another longer-term study of $\mathrm{T}$ therapy in 1023 hypogonadal men, with a mean follow-up of 5 years, there were 11 cases of $\mathrm{PCa}(1.08 \%)$ - a prevalence figure lower than that reported by two large screening studiesthe Prostate, Lung, Colorectal, and Ovarian (PLCO) Cancer Screening Trial (7.35\%) and the European Randomized Study of Screening for PCa (ERSPC) (9.6\%). An important limitation of this study was that younger men were included, unlike the PLCO and ERSPC trials. ${ }^{28}$

In a case-control study in the United States, using a Surveillance, Epidemiology and End Results (SEER) Medicare-linked database, patients with a diagnosis of PCa and with history of T use (574 men) were compared with PCa patients without history of $\mathrm{T}$ use $(51,945)$. Those patients who had received TRT in the 5 years before diagnosis were found not to have an increased risk of high-grade disease at diagnosis (odds ratio [OR] 0.84, 95\% CI 0.67-1.05). A multivariable analysis to assess a dose-response association among $\mathrm{T}$ users also did not reveal any correlation (OR 1.00, 95\% CI 0.99-1.01). ${ }^{29}$ 
Another retrospective study evaluated 247 patients in Texas who commenced $\mathrm{T}$ therapy for a mean followup period of 6.5 years and compared them with 211 patients who did not receive TRT. By the end of the study, 47 men developed cancer: 27 (12.8\%) not on TRT and $20(8.1 \%)$ on TRT. No significant difference in PCa risk was found to be associated with TRT (HR 1.2, 95\% CI $0.54-2.50$ ).

In a similar report, from Sweden, Loeb et al. reported the results of a nested case-control study using the National PCa Registry of Sweden. From a multivariate analysis, no significant difference was demonstrated in PCa risk in patients with TRT exposure (OR 1.03; 95\% CI 0.90-1.17). The authors went on to report that patients who had received TRT were observed to have more favorable-outcome PCa (OR 1.35; 95\% CI 1.161.56 ) and a lower risk of aggressive cancer (OR 0.50; 95\% CI 0.37-0.67) (28447913). ${ }^{30}$

In their study of 776 hypogonadal men with negative PCa screening at enrollment, Zhang et al. argued that TRT may accelerate the diagnosis of occult cancer, but not affect the overall prevalence at 7-year followup. They studied two groups of hypogonadal men with negative PCa screenings according to the European Association of Urology (EAU) guidelines. No significant difference was observed between the TRT group and the non-TRT group in cancer incidence at the end of the study period (9/398 vs. 5/230 respectively, $p=0.9999$ ), even after performing propensity score matching to account for differences in baseline characteristics, most notably age and PSA. Of note, all cases in the TRT group were diagnosed within 18 months of treatment initiation, as compared with all cases diagnosed in the non-TRT group after 24 months of enrollment. ${ }^{31}$ The authors concluded that TRT may speed up the diagnosis of occult cancer already present at initiation of treatment, but the therapy had a protective effect from the end of their predefined latency period until the end of the study. ${ }^{31}$ Limitations of the study included a small subject number and aggressive lab testing/screening of the treatment group. Indeed, ongoing tri-annual transrectal ultrasound and digital rectal exam could be a potential explanation for the earlier cancer diagnosis.

In a recent meta-analysis of 26 placebo-controlled trials studying the effect of TRT on PCa, there was minimal absolute change of PSA between the beginning and end of the trial $(0.1 \mathrm{ng} / \mathrm{mL}, 95 \% \mathrm{CI}-0.28$ to 0.48$).{ }^{32}$ A major limitation of this result was the short median trial duration of 196 days. The same group reviewed 11 trials to estimate the risk of PCa diagnosis while on TRT, and they concluded that there was no significant increase in risk measured by pooled OR $(0.87,95 \%$ CI $0.3-2.5)$. They also did not find evidence for heterogeneity or publication bias when assessing the quality of the results. ${ }^{32}$

In a similar analysis, data were pooled from randomcontrolled trials (RCTs) but divided into two groups: short-term follow-up (less than 12 months) and longterm follow-up (12-36 months). Pooling data from the RCTs with short-term follow-up did not show an increased PCa diagnosis rate, with OR of 0.39 (95\% CI 0.06-2.45; $\mathrm{P} 1 / 40.32$ ) for the study using injectable $\mathrm{T}$ and 1.10 (95\% CI $0.26-4.65$; P 1/4 0.90) for the study using transdermal T. However, these studies did find a rise in PSA with a standard mean difference of 0.52 (95\% CI 0.00-1.05, $p=0.05$ ) in studies using injectable $\mathrm{T}$ and a standard mean difference of 0.33 (95\% CI 0.21-0.45, $p=0.00001$ ) for studies using transdermal T. For RCTs with a longer-term follow-up, no difference in PCa diagnosis between the treatment and placebo group 0.99 (95\% CI 0.24-4.02; $p=0.99$ ) was determined. ${ }^{33}$

\section{TRT in Patients with Untreated PCa}

Several recent retrospective studies described in this sub-section have evaluated the risk associated with TRT in hypogonadal men with untreated PCa undergoing AS. ${ }^{34-38}$ In general, these studies are limited by their retrospective design, few participants, and short follow-up periods (Table 1).

Two trials have demonstrated that a subset of men presenting with $\mathrm{PCa}$ had both an improvement in symptomatic hypogonadism and PCa characteristics after $\mathrm{T}$ administration. ${ }^{39,40}$ Researchers from one 2009 study treated 15 PCa patients with three progressively increasing doses of transdermal T. Three patients saw a decline in PSA, though a total of 12 patients were taken off the study after possible disease progression, as evaluated through either PSA increases or findings on imaging studies. ${ }^{39}$

In an analysis of SEER Medicare data, Kaplan et al. estimated that, between 1991 and 2007, 0.79\% (1181/ 149,354 men) of men received exogenous $\mathrm{T}$ after a PCa diagnosis. Several statistically significant findings were presented: Men on AS were noted to be less likely to receive TRT overall (6.9 vs. 5.4 events per 100person years, $p=0.0001$ ), and cancer-related mortality was higher in the non-TRT groups when compared with the TRT group (1.6 vs. 0.9 events per 100-person years, $p<0.0001){ }^{41}$ Limitations of the study included 


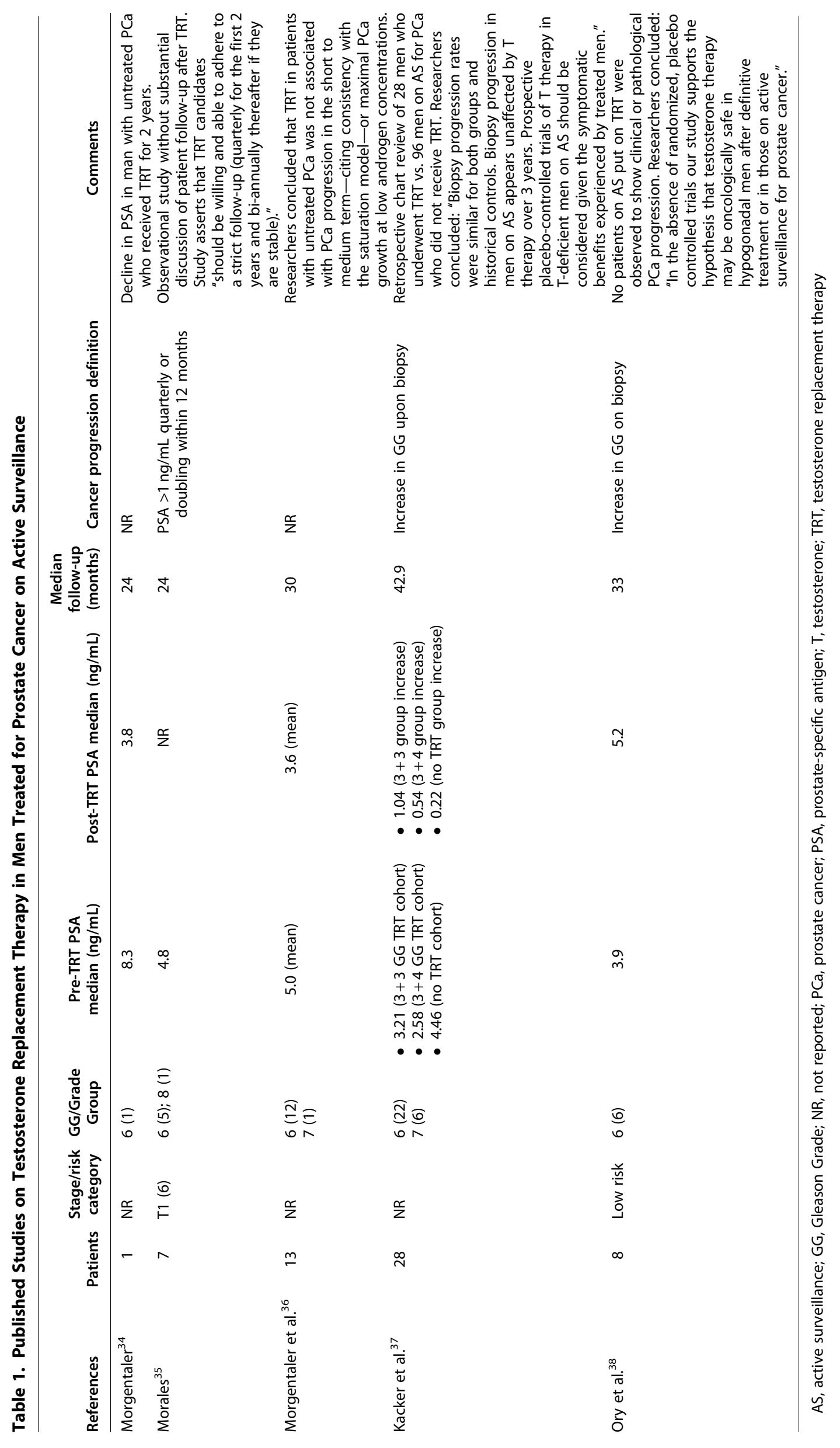


only evaluating a 5-year follow-up period and potentially unreliable clinical information available in a claims-based database.

Morgentaler et al. reported the results of prostate biopsies, serum PSA, and prostate volume in 13 hypogonadal men on AS who received TRT for 6 months for untreated PCa for 2.5 years. ${ }^{36}$ Although the men experienced a 2.8 -fold increase in serum $\mathrm{T}$ levels $(238-664 \mathrm{ng} / \mathrm{dL} ; p<0.001)$, there was no significant change in mean PSA $(5.5 \pm 6.4$ at initial biopsy vs. $3.6 \pm 2.6 \mathrm{ng} / \mathrm{mL}$ after TRT, $p=0.29)$. These researchers noted that all men receiving TRT also experienced symptomatic improvement in libido, sexual performance, mood, and energy.

\section{TRT in Patients with Treated PCa}

Tables 2 and 3 summarize the published series on TRT after PCa treated with RP and radiotherapy modalities, respectively. ${ }^{42-49}$ Recent studies have confirmed that TRT after definitive treatment for localized PCa appears safe and does not lead to increased disease recurrence.

In a large cohort analysis utilizing the Veterans Affairs Informatics and Computing Infrastructure (VINCI) database, Sarkar et al. identified 69,984 men with localized PCa, of whom 28,651 underwent RP and 41,333 received radiation. Of this total number, $469 \mathrm{RP}(1.64 \%)$ and 543 radiation (1.31\%) patients received TRT with a median follow-up of almost 7 years. ${ }^{50}$ The investigators found that comparing those men who received TRT with those who did not, there were no between-group differences in BCR, PCa-specific mortality, or overall mortality after surgery (HR: 1.07; HR: 0.72 [ $p=0.43]$; and HR: 1.11 [ $p=0.43]$, respectively) or radiation (HR: 1.07; HR: 1.02 [ $p=0.95]$; and HR: 1.02 $[p=0.86]$, respectively). One strength of this study was that it pooled a large, multi-ethnic, nationwide cohort with a high prevalence of African American men (24\% prostatectomy, $28 \%$ radiation).

Ahlering et al. examined the rates of BCR in 850 patients who underwent RP for localized $\mathrm{PCa}$, of whom $152(18 \%)$ were started on TRT compared with 419 (82\%) proportionally matched controls. After a median follow-up of 3.5 years, BCR occurred in 11 out of 152 $(7.2 \%)$ and 53 out of $419(12.6 \%)$ patients in the TRT and control groups, respectively. In adjusted time-toevent analysis, TRT was an independent predictor of recurrence-free survival. After accounting for the Gleason grade (GG) group, pathological stage, preoperative PSA level, and calculated free $\mathrm{T}$, the authors determined that patients prescribed TRT were $\sim 54 \%$ less likely to recur (HR 0.54, 95\% CI $0.292-$ 0.997). ${ }^{51}$ Among those men who would eventually recur, TRT appeared to delay time to recurrence by an average of 1.5 years. Importantly, this study reported that by 2 years post-RP, $96 \%$ of patients had re-gained erectile function.

Specifically regarding hypogonadal men who underwent curative treatment for high-risk PCa, Teeling et al. conducted a single-arm meta-analysis to determine the relationship between TRT and risk of BCR. In this analysis of 13 studies and 109 men, the BCR rate was $0.00 \%(0.00-0.05 \%)$, lower than the expected rate for high-risk $\mathrm{PCa}$ survivors, suggesting that $\mathrm{T}$ therapy may not increase BCR risk in this patient population. The authors strongly cautioned against over interpretation, seeing that the available body of evidence was of very low quality. ${ }^{52}$

Another meta-analysis sought to evaluate the association between TRT in nonmetastatic PCa patients after definitive local therapy and the rate of BCR. Twenty-one studies were included with an overall pooled BCR rate of 0.01 (95\% CI $0.00-0.02)$, suggesting a lack of association between TRT and BCR. ${ }^{53} \mathrm{In}$ subgroup analyses, pooled BCR rates were $0.00 \%$ $(95 \%$ CI $0.00-0.02)$ in patients treated with RP and $0.02 \%(95 \%$ CI $0.00-0.04)$ in patients treated with external beam radiotherapy, brachytherapy (BT), cryotherapy, or HIFU. No heterogeneity was observed among included studies or in the subgroup analyses. A meta-analysis of 21 studies of BCR of PCa in men prescribed TRT after initiation of cancer therapy revealed that TRT in the setting of definitive PCa treatment did not increase BCR risk. Although studies varied in their PSA cutoff point for BCR, the majority (13/21) used the Phoenix definition of nadir $+2 \mathrm{ng} / \mathrm{mL}$ as the end point. The researchers supported their conclusions with an identified BCR rate of $0.01 \%$ after TRT. ${ }^{54}$

Another study monitored $\mathrm{PCa}$ in 13 hypogonadal men who received TRT after previous BT or external beam radiotherapy treatment between 2006 and 2011. ${ }^{55}$ After a median follow-up time of 29.7 months, no significant increases in PSA were observed during the study period $(0.16-1.35 \mathrm{ng} / \mathrm{mL}, p=0.345)$, and no reported cases of BCR were reported. Pastuszak et al. also organized a multicenter study that identified 98 men diagnosed with $\mathrm{PCa}$ and treated with radiation therapy. While on TRT for a median follow-up of 40.8 months, the men experienced a statistically significant median rise of $211 \mathrm{ng} / \mathrm{mL}$ in T levels and a nonsignificant increase in PSA from $0.08 \mathrm{ng} / \mathrm{mL}$ at baseline 

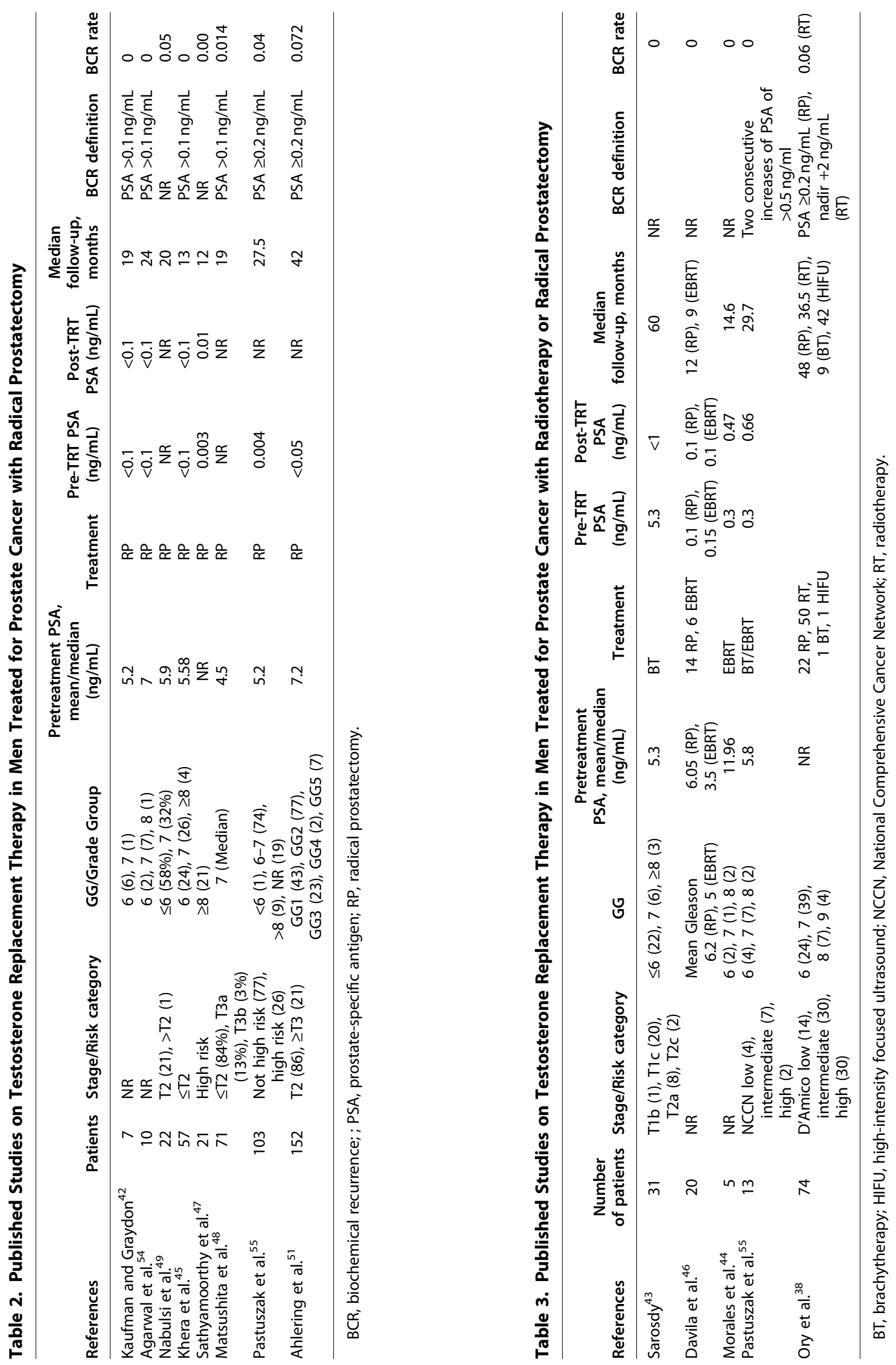
to $0.09 \mathrm{ng} / \mathrm{mL}(p=0.05)$. Six men $(6.1 \%)$ experienced BCR and three of these men underwent BT before PSA levels consequently normalized. ${ }^{56}$

In 20 men (49-74 age range) who underwent BT for PCa $(6.2 \mathrm{ng} / \mathrm{mL}$ PSA at time of diagnosis), there was a decrease in mean PSA level, from $0.7 \mathrm{ng} / \mathrm{mL}$ before TRT to $0.1 \mathrm{ng} / \mathrm{mL}$ after TRT (TRT not initiated before at least 3 months of treatment) at the time of last followup (median time of 31 months). ${ }^{57}$ Patients received longacting $1000 \mathrm{mg} \mathrm{T}$ injections and subsequent adjusted $\mathrm{T}$ concentration injections to meet a free $\mathrm{T}$ concentration $>11.7 \mathrm{ng} / \mathrm{dL}$. Another small study of five patients also identified benefits of TRT administration in hypogonadal patients following external beam radiotherapy for localized PCa. Patients began TRT once their PSA levels reached their nadir and only one patient had a transitory PSA level increase, not more than $1.5 \mathrm{ng} / \mathrm{mL}{ }^{35}$ All men reported improvements in symptoms associated with hypogonadism.

\section{TRT in Patients with Advanced PCa}

In the setting of metastatic castration-resistant $\mathrm{PCa}$ (mCRPC), an emerging body of literature supports the use of supraphysiologic levels of androgens as an adjunctive therapeutic treatment. Although the exact mechanism remains under active investigation, it appears that high-dose androgen may act by inducing doublestrand DNA breaks, inhibiting relicensing of DNA in cells expressing high levels of AR repressing genes in DNA repair, downregulating AR splice variants (e.g., AR-V7), and delaying restoration of damaged DNA. ${ }^{26,58-62}$ Both continuous and intermittent administration of high-dose testosterone (HDT) has been described, with a greater body of literature available for the latter. This intermittent HDT strategy, where T levels are quickly raised to supraphysiologic levels and then brought down to near-castration levels over $\sim 1$ month, is termed bipolar androgen therapy (BAT).

Multiple recent Phase I and II studies have been conducted to investigate TRT in the CRPC setting. The first Phase I trial evaluated the effect of increasing doses of transdermal $\mathrm{T}(2.5,5$, or $7.5 \mathrm{mg} /$ day $)$ in 15 men with low-risk CRPC. The authors observed that one patient had symptomatic progression, and three patients had a decrease in PSA (maximums decrease of $43 \%)^{39}$ Those men receiving the highest dose of TRT demonstrated a longer time to progression, which was not noted to be statistically significant. No grade 3 or 4 toxicities were reported apart from one patient with cardiac toxicity at week 53 .

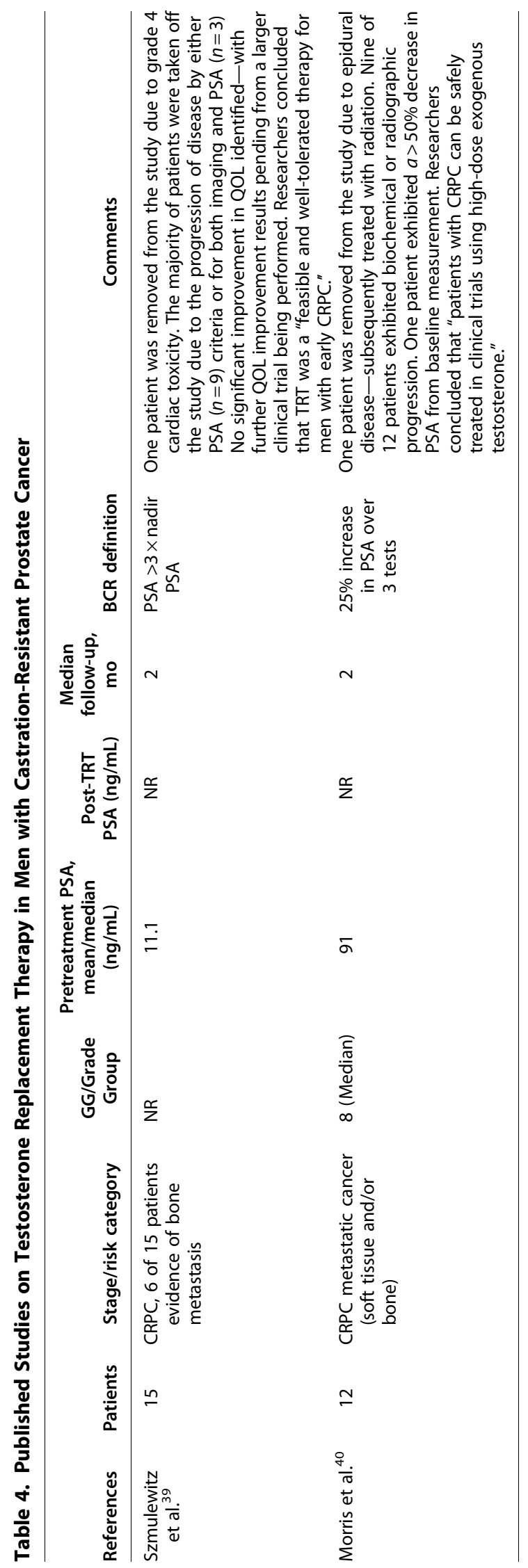


The second Phase I study examined 12 men with CRPC administered transdermal TRT ( $7.5 \mathrm{mg} /$ day) for 1 week, 1 month, or until disease progression. ${ }^{40}$ Despite the goal of reaching supraphysiologic levels of $\mathrm{T}$ during the study, average serum $\mathrm{T}$ levels were within normal limits. Although no objective responses were observed, $33 \%$ of patients had declines of PSA of at least $20 \%$ and one reached $a>50 \%$ decline in PSA (PSA50). There were no grade 3 or 4 toxicities. Results from these aforementioned Phase I studies are presented in Table 4.

Subsequently, the Phase II TRANSFORMER trial examined 30 asymptomatic mCRPC patients with disease progression on abiraterone/enzalutamide who were treated with BAT and then re-challenged with enzalutamide. $^{63}$ The study reported a $30 \%$ PSA50 response to BAT. Twenty-one patients proceeded to enzalutamide re-challenge with a 52\% PSA50 response. This study appears to support the use of BAT as a means of targeting the AR in patients who have disease progression on second-line AR signaling inhibitors.

The currently ongoing RESTORE Phase II trial has enrolled 59 asymptomatic mCRPC patients with disease progression on abiraterone $(n=29)$ or enzalutamide $(n=30)$ who were then treated with BAT and rechallenged with their most recent androgen receptortargeted therapy. ${ }^{62}$ After BAT, the postenzalutamide cohort showed a $30 \%$ PSA50 response versus $17 \%$ PSA50 in the postabiraterone cohort, a difference that was not statistically significant. After AR targeted therapy re-challenge, PSA50 response was significantly higher in the postenzalutamide cohort (68\% vs. $16 \%$ ). Median progression free survival (PFS) was longer in the postenzalutamide versus postabiraterone rechallenge cohort (12.8 months vs. 8.1 months). The authors also noted that men with detectable AR-V7 mutations in circulating-tumor DNA had worse PFS (10.3 months vs. 7.1 months). From the currently reported data, BAT appears to demonstrate clinical benefit in pretreated mCRPC patients with a greater re-sensitization seen in men treated with enzalutamide compared with abiraterone and that the presence of certain splice variants such as AR-V7 may prognose a worse response to BAT. ${ }^{62}$

\section{Conclusion}

The TRT for patients who have a history of untreated or treated PCa remains a debated practice, given the long-established dogma that $\mathrm{T}$ could act as "fuel on the fire" for PCa recurrence and growth. As previously described, this paradigm has shifted since the introduction of the saturation model hypothesis. Since then, a growing body of published case series appear to support TRT in this clinical setting. Researchers currently recommend that patients be prescribed the lowest necessary $\mathrm{T}$ dose to achieve serum androgen normalization and then be screened at regular intervals, depending on the administration method.

The American Urological Association (AUA) TRT guidelines recognize the lack of evidence linking TRT to the development of $\mathrm{PCa}$, as well as insufficient evidence to quantify a risk-benefit ratio of TRT in patients with a history of PCa. ${ }^{64}$ As such, hypogonadal patients should make an informed consent before initiating TRT, after a thorough conversation with their provider of the risks and benefits. Until definitive evidence from long-term prospective or placebo-controlled RCTs becomes available, patients under AS, or with a history of PCa must understand the importance of strict compliance with increased T, PSA, and digital rectal exam monitoring frequency.

Currently, neither the AUA nor EAU provides guidelines on monitoring intervals for TRT patients on AS or after RP or radiation therapy. Data from available studies indicate that serum T, PSA, and digital rectal exam findings should be evaluated at least every 3-6 months, according to a physician's best judgment given a patient's goals, medical history, and perceived PCa risk. ${ }^{65}$ For patients on AS, it has been suggested that a patient's relative risk be evaluated by a multidisciplinary medical team, including a urologist, endocrinologist, and oncologist. ${ }^{66}$ In all cases, serum $\mathrm{T}$ levels should be kept as low as possible to meet a patient's replacement needs.

Future studies, in addition to focusing on specific PCa risk with TRT in populations stratified by factors such as GG group, treatment during AS, or history of prior definitive treatment for localized $\mathrm{PCa}$, should also focus on providing results of quality-of-life metrics to help enumerate the risk-benefit ratio for patients when making health care decisions.

\section{Authors' Contributions}

Conception and design: W.J.G.H.; Data acquisition and analysis: M.P. and I.V.; Drafting article: M.P. and I.V.; Revising article: A.S. and W.J.G.H.; Approval: All authors.

\section{Author Disclosure Statement}

No competing financial interests exist. 


\section{Funding Information}

No funding was received for this article.

\section{References}

1. American Cancer Society. Cancer Facts \& Figures 2020. https://www .cancer.org/research/cancer-facts-statistics/all-cancer-facts-figures/ cancer-facts-figures-2020.html. Accessed August 15, 2020.

2. Klotz $L$, Vesprini $D$, Sethukavalan $P$, et al. Long-term follow-up of a large active surveillance cohort of patients with prostate cancer. J Clin Oncol. 2015;33(3):272-277.

3. Soloway MS, Soloway CT, Williams S, Ayyathurai R, Kava B, Manoharan M. Active surveillance; a reasonable management alternative for patients with prostate cancer: The Miami experience. BJU Int. 2008;101(2): 165-169.

4. Roemeling S, Roobol MJ, de Vries $\mathrm{SH}$, et al. Active surveillance for prostate cancers detected in three subsequent rounds of a screening trial: Characteristics, PSA doubling times, and outcome. Eur Urol. 2007;51(5): 1244-1250; discussion 1251.

5. Khatami A, Aus G, Damber JE, Lilja H, Lodding P, Hugosson J. PSA doubling time predicts the outcome after active surveillance in screening-detected prostate cancer: Results from the European randomized study of screening for prostate cancer, Sweden section. Int J Cancer. 2007;120(1):170-174.

6. Pastuszak AW, Pearlman AM, Lai WS, et al. Testosterone replacement therapy in patients with prostate cancer after radical prostatectomy. J Urol. 2013;190(2):639-644.

7. Arcangeli G, Strigari L, Arcangeli S, et al. Retrospective comparison of external beam radiotherapy and radical prostatectomy in high-risk, clinically localized prostate cancer. Int J Radiat Oncol Biol Phys. 2009;75(4): 975-982.

8. Mulligan T, Frick MF, Zuraw QC, Stemhagen A, McWhirter C. Prevalence of hypogonadism in males aged at least 45 years: The HIM study. Int J Clin Pract. 2006;60(7):762-769.

9. Traish AM, Miner MM, Morgentaler A, Zitzmann M. Testosterone deficiency. Am J Med. 2011;124(7):578-587.

10. Kim HJ, Kim BH, Park $\mathrm{CH}, \mathrm{Kim} \mathrm{Cl}$. Usefulness of preoperative serum testosterone as a predictor of extraprostatic extension and biochemical recurrence. Korean J Urol. 2012;53(1):9-13.

11. Salonia A, Gallina A, Briganti A, et al. Preoperative hypogonadism is not an independent predictor of high-risk disease in patients undergoing radical prostatectomy. Cancer. 2011;117(17):3953-3962.

12. Teloken C, Da Ros CT, Caraver F, Weber FA, Cavalheiro AP, Graziottin TM. Low serum testosterone levels are associated with positive surgical margins in radical retropubic prostatectomy: Hypogonadism represents bad prognosis in prostate cancer. J Urol. 2005;174(6):2178-2180.

13. Kaplan AL, Lenis AT, Shah A, Rajfer J, Hu JC. Testosterone replacement therapy in men with prostate cancer: A time-varying analysis. J Sex Med. 2015;12(2):374-380.

14. Umbas $R$, Sugiono $M$. Testosterone replacement therapy in prostate cancer patients: Is it safe? Acta Med Indones. 2010;42(3):171-175.

15. Nguyen TM, Pastuszak AW. Testosterone therapy among prostate cancer survivors. Sex Med Rev. 2016:4(4):376-388.

16. Oesterling JE. Prostate specific antigen: A critical assessment of the most useful tumor marker for adenocarcinoma of the prostate. J Urol. 1991; 145(5):907-923

17. Johnson DE, Prout GR, Scott WW, Schmidt JD, Gibbons RP. Clinical significance of serum acid phosphatase levels in advanced prostatic carcinoma. Urology. 1976;8(2):123-126.

18. Morgentaler A, Bruning CO, III, DeWolf WC. Occult prostate cancer in men with low serum testosterone levels. JAMA. 1996;276(23):1904-1906.

19. Morgentaler A, Rhoden EL. Prevalence of prostate cancer among hypogonadal men with prostate-specific antigen levels of $4.0 \mathrm{ng} / \mathrm{mL}$ or less. Urology. 2006;68(6):1263-1267.

20. Levine LA, Estrada CR, Morgentaler A. Mechanical reliability and safety of, and patient satisfaction with the Ambicor inflatable penile prosthesis: Results of a 2 center study. J Urol. 2001;166(3):932-937.

21. Traish AM, Williams DF, Hoffman ND, Wotiz HH. Validation of the exchange assay for the measurement of androgen receptors in human and dog prostates. Prog Clin Biol Res. 1988;262:145-160.
22. Traish AM, Muller RE, Wotiz $\mathrm{HH}$. A new procedure for the quantitation of nuclear and cytoplasmic androgen receptors. J Biol Chem. 1981;256(23): 12028-12033.

23. Rastrelli G, Corona G, Vignozzi L, et al. Serum PSA as a predictor of testosterone deficiency. J Sex Med. 2013;10(10):2518-2528.

24. Cooper CS, Perry PJ, Sparks AE, Maclndoe JH, Yates WR, Williams RD. Effect of exogenous testosterone on prostate volume, serum and semen prostate specific antigen levels in healthy young men. J Urol. 1998;159(2): 441-443.

25. Marks LS, Mazer NA, Mostaghel E, et al. Effect of testosterone replacement therapy on prostate tissue in men with late-onset hypogonadism: A randomized controlled trial. JAMA. 2006;296(19):2351-2361.

26. Chatterjee P, Schweizer MT, Lucas JM, et al. Supraphysiological androgens suppress prostate cancer growth through androgen receptormediated DNA damage. J Clin Invest. 2019;129(10):4245-4260.

27. Santella C, Renoux C, Yin H, Yu OHY, Azoulay L. Testosterone replacement therapy and the risk of prostate cancer in men with late-onset hypogonadism. Am J Epidemiol. 2019;188(9):1666-1673.

28. Haider A, Zitzmann $M$, Doros $G$, Isbarn $H$, Hammerer $P$, Yassin A. Incidence of prostate cancer in hypogonadal men receiving testosterone therapy: Observations from 5-year median followup of 3 registries. J Urol. 2015; 193(1):80-86.

29. Baillargeon J, Kuo YF, Fang X, Shahinian VB. Long-term exposure to testosterone therapy and the risk of high grade prostate cancer. J Urol. 2015;194(6):1612-1616.

30. Loeb S, Folkvaljon Y, Damber JE, Alukal J, Lambe M, Stattin

$P$. Testosterone replacement therapy and risk of favorable and aggressive prostate cancer. J Clin Oncol. 2017;35(13):1430-1436.

31. Zhang X, Zhong Y, Saad F, Haider K, Haider A, Xu X. Clinically occult prostate cancer cases may distort the effect of testosterone replacement therapy on risk of PCa. World J Urol. 2019;37(10):2091-2097.

32. Boyle $P$, Koechlin A, Bota $M$, et al. Endogenous and exogenous testosterone and the risk of prostate cancer and increased prostate-specific antigen (PSA) level: A meta-analysis. BJU Int. 2016;118(5):731-741.

33. Cui $Y$, Zong $H$, Yan $H$, Zhang $Y$. The effect of testosterone replacement therapy on prostate cancer: A systematic review and meta-analysis. Prostate Cancer Prostatic Dis. 2014;17(2):132-143.

34. Morgentaler A. Two years of testosterone therapy associated with decline in prostate-specific antigen in a man with untreated prostate cancer. J Sex Med. 2009;6(2):574-577.

35. Morales A. Effect of testosterone administration to men with prostate cancer is unpredictable: A word of caution and suggestions for a registry. BJU Int. 2011;107(9):1369-1373.

36. Morgentaler A, Lipshultz LI, Bennett R, Sweeney M, Avila D, Jr, Khera M. Testosterone therapy in men with untreated prostate cancer. J Urol. 2011; 185(4):1256-1260.

37. Kacker R, Hult M, San Francisco IF, et al. Can testosterone therapy be offered to men on active surveillance for prostate cancer? Preliminary results. Asian J Androl. 2016;18(1):16-20.

38. Ory J, Flannigan R, Lundeen C, Huang JG, Pommerville P, Goldenberg SL. Testosterone therapy in patients with treated and untreated prostate cancer: Impact on oncologic outcomes. J Urol. 2016;196(4):1082-1089.

39. Szmulewitz R, Mohile S, Posadas E, et al. A randomized phase 1 study of testosterone replacement for patients with low-risk castration-resistant prostate cancer. Eur Urol. 2009;56(1):97-103.

40. Morris MJ, Huang D, Kelly WK, et al. Phase 1 trial of high-dose exogenous testosterone in patients with castration-resistant metastatic prostate cancer. Eur Urol. 2009;56(2):237-244.

41. Kaplan AL, Trinh QD, Sun M, et al. Testosterone replacement therapy following the diagnosis of prostate cancer: Outcomes and utilization trends. J Sex Med. 2014;11(4):1063-1070.

42. Kaufman JM, Graydon RJ. Androgen replacement after curative radical prostatectomy for prostate cancer in hypogonadal men. J Urol. 2004; 172(3):920-922

43. Sarosdy MF. Testosterone replacement for hypogonadism after treatment of early prostate cancer with brachytherapy. Cancer. 2007;109(3): 536-541.

44. Morales A, Black AM, Emerson LE. Testosterone administration to men with testosterone deficiency syndrome after external beam radiotherapy for localized prostate cancer: Preliminary observations. BJU Int. 2009; 103(1):62-64 
45. Khera M, Grober ED, Najari B, et al. Testosterone replacement therapy following radical prostatectomy. J Sex Med. 2009;6(4):1165-1170.

46. Davila HH AC, Hall MK, Salup R, Lockhart JM, Carrion RE. Analysis of the PSA response after testosterone supplementation in patients who have previously received management for their localized prostate cancer. J Urol. 2008(179):428.

47. Sathyamoorthy K, Stein M, Lipshultz L, Khera M. Follow-up series of testosterone replacement therapy following radical prostatectomy: The Baylor experience. J Sex Med. 2010;7:10-11.

48. Matsushita K, Katz D, Stember D, Nelson C, Mulhall J. Analysis of the safety and efficacy of testosterone suplementation following radical prostatectomy. J Sex Med. 2012;9:205.

49. Nabulsi O, Tal R, Gotto G, Narus J, Goldenberg L, Mulhall JP. Outcomes analysis of testosterone supplementation in hypogonadal men following radical prostatectomy. J Urol. 2008(179):426-427.

50. Sarkar RR, Patel SH, Parsons JK, et al. Testosterone therapy does not increase the risks of prostate cancer recurrence or death after definitive treatment for localized disease. Prostate Cancer Prostatic Dis. 2020;23(4): 689-695.

51. Ahlering TE, My Huynh $L$, Towe $M$, et al. Testosterone replacement therapy reduces biochemical recurrence after radical prostatectomy. BJU Int. 2020;126(1):91-96.

52. Teeling F, Raison N, Shabbir M, Yap T, Dasgupta P, Ahmed K. Testosterone therapy for high-risk prostate cancer survivors: A systematic review and meta-analysis. Urology. 2019;126:16-23.

53. Kardoust Parizi M, Abufaraj $M$, Fajkovic $\mathrm{H}$, et al. Oncological safety of testosterone replacement therapy in prostate cancer survivors after definitive local therapy: A systematic literature review and meta-analysis. Urol Oncol. 2019;37(10):637-646.

54. Agarwal PK, Oefelein MG. Testosterone replacement therapy after primary treatment for prostate cancer. J Urol. 2005;173(2):533-536.

55. Pastuszak AW, Pearlman AM, Godoy G, Miles BJ, Lipshultz LI, Khera M. Testosterone replacement therapy in the setting of prostate cancer treated with radiation. Int J Impot Res. 2013;25(1):24-28.

56. Pastuszak AW, Khanna A, Badhiwala N, et al. Testosterone therapy after radiation therapy for low, intermediate and high risk prostate cancer. J Urol. 2015;194(5):1271-1276.

57. Balbontin FG, Moreno SA, Bley E, Chacon R, Silva A, Morgentaler A. Longacting testosterone injections for treatment of testosterone deficiency after brachytherapy for prostate cancer. BJU Int. 2014;114(1):125-130.

58. Murthy S, Wu M, Bai VU, et al. Role of androgen receptor in progression of LNCaP prostate cancer cells from G1 to S phase. PLoS One. 2013;8(2):e56692.

59. D'Antonio JM, Vander Griend DJ, Isaacs JT. DNA licensing as a novel androgen receptor mediated therapeutic target for prostate cancer. Endocr Relat Cancer. 2009;16(2):325-332.

60. Litvinov IV, Vander Griend DJ, Antony L, et al. Androgen receptor as a licensing factor for DNA replication in androgen-sensitive prostate cancer cells. Proc Natl Acad Sci U S A. 2006;103(41):15085-15090.

61. Haffner MC, Aryee MJ, Toubaji A, et al. Androgen-induced TOP2Bmediated double-strand breaks and prostate cancer gene rearrangements. Nat Genet. 2010;42(8):668-675.

62. Markowski MC, Wang H, Sullivan R, et al. A Multicohort Open-label Phase II Trial of Bipolar Androgen Therapy in Men with Metastatic Castration- resistant Prostate Cancer (RESTORE): A Comparison of post-abiraterone versus post-enzalutamide cohorts. Eur Urol. 2020. [Epub ahead of print] DOI: 10.1016/j.eururo.2020.06.042.

63. Teply BA, Wang H, Luber B, et al. Bipolar androgen therapy in men with metastatic castration-resistant prostate cancer after progression on enzalutamide: An open-label, phase 2, multicohort study. Lancet Oncol. 2018;19(1):76-86.

64. Mulhall JP, Trost LW, Brannigan RE, et al. Evaluation and management of testosterone deficiency: AUA Guideline. J Urol. 2018;200(2):423-432.

65. Gray H, Seltzer J, Talbert RL. Recurrence of prostate cancer in patients receiving testosterone supplementation for hypogonadism. Am J Health Syst Pharm. 2015;72(7):536-541.

66. Lenfant L, Leon P, Cancel-Tassin G, et al. Testosterone replacement therapy (TRT) and prostate cancer: An updated systematic review with a focus on previous or active localized prostate cancer. Urol Oncol. 2020; 38(8):661-670.

Cite this article as: Polchert M, Voznesensky I, Soubra A, Hellstrom WJG (2020) Updated review of testosterone replacement therapy in the setting of prostate cancer, Androgens: Clinical Research and Therapeutics 2.1, 36-45, DOI: 10.1089/andro.2020.0013.

$\begin{aligned} & \quad \text { Abbreviations Used } \\ & \mathrm{AR}=\text { androgen receptor } \\ & \mathrm{AS}=\text { active surveillance } \\ & \mathrm{AUA}=\text { American Urological Association } \\ & \mathrm{BAT}=\text { bipolar androgen therapy } \\ & \mathrm{BCR}=\text { biochemical recurrence } \\ & \mathrm{BT}=\text { brachytherapy } \\ & \mathrm{CRPC}=\text { castration-resistant prostate cancer } \\ & \mathrm{EAU}=\text { European Association of Urology } \\ & \mathrm{ERSPC}=\text { European Randomized Study of Screening for PCa } \\ & \mathrm{HDT}=\text { high-dose testosterone } \\ & \mathrm{HIFU}=\text { high-intensity focused ultrasound } \\ & \mathrm{HR}=\text { hazard ratio } \\ & \mathrm{mCRPC}=\text { metastatic castration-resistant PCa } \\ & \mathrm{PAP}=\text { prostatic acid phosphatase } \\ & \mathrm{PCa}=\text { prostate cancer } \\ & \mathrm{PLCO}=\text { Prostate, Lung, Colorectal, and Ovarian } \\ & \mathrm{PSA}=\text { prostate-specific antigen } \\ & \mathrm{RCT}=\text { random-controlled trial } \\ & \mathrm{RP}=\text { radical prostatectomy } \\ & \mathrm{RT}=\text { radiotherapy } \\ & \mathrm{SEER}=\text { Surveillance, Epidemiology and End Results } \\ & \mathrm{T}=\text { testosterone } \\ & \mathrm{TRT}=\text { testosterone replacement therapy }\end{aligned}$

Publish in Androgens: Clinical Research and Therapeutics

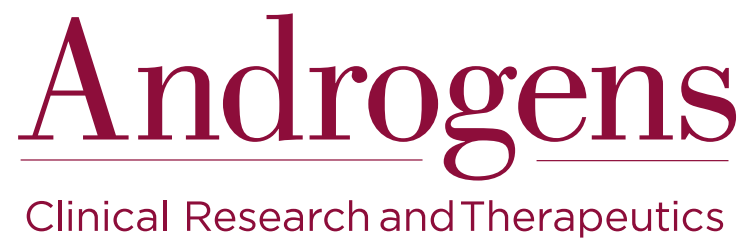

liebertpub.com/andro 